\section{Unilateral Acute Idiopathic Maculopathy Associated with Hand-Foot-Mouth Disease}

Unilateral acute idiopathic maculopathy (UAIM) is a rare disorder that has been linked with coxsackie virus. It was initially described by Yannuzzi et al. [1] in a series of 9 patients in 1991. A viral prodrome is common. We aim to add to the literature a case of challenging visual symptoms associated with resolved hand-footmouth disease, suggesting presumed UAIM.

A 51-year-old male, with no significant past ocular or medical history, complained of distortion and noticed 4 persistent small round defects in the center of his vision in the left eye. He presented to our practice 5 months after the onset of symptoms, which had been unchanged during that time span. Notably, two months prior to the onset of visual symptoms, the patient had had multiple erythematous vesicular lesions on the palms of his hands and the soles of his feet. $\mathrm{He}$ also had pharyngitis, along with vesicles around the mouth. No antibody testing for coxsackie virus was done at the time. By the time of his presentation with visual complaints, these symptoms had resolved.

On examination, the patient presented with best corrected visual acuity $20 / 20$ OD and 20/25 OS. His manifest refraction was -2.50 sphere OU. Intraocular pressure was $12 \mathrm{OD}$ and $14 \mathrm{OS}$. There was no evidence of intraocular inflammation. Anterior segment was unremarkable. Fundus examination revealed hyperpigmented spots surrounded by hypopigmented atrophic changes in the left macula (Figure 1). Fluorescein angiography revealed early blockage and window defect corresponding to the pigmentary changes (Figure 2). OCT imaging showed thickening at the level of the outer retina and IS/OS line disruption at the site of these spots (Figure 3).

In cases of unilateral acute idiopathic maculopathy, typical funduscopic evaluation reveals retinal edema with yellowish-white exudative changes that eventually become hypopigmented spots with absence of exudation $[1,2]$. Initial fluorescein angiography reveals hyperfluorescence secondary to staining at the level of the retinal pigment epithelium (RPE). At later stages, RPE atrophy develops and fluorescein angiography reveals hypofluorescence

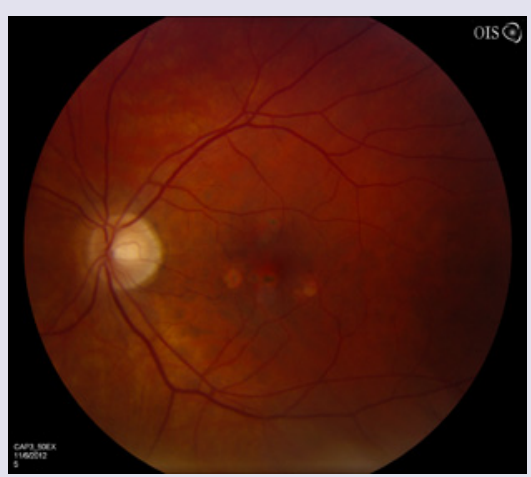

Figure 1:

\section{Journal of}

\section{Ocular Biology}

\section{Sheyman A, Pahk P and Tannen B*}

Department of Ophthalmology, Mount Sinai School of Medicine, New York, NY, USA

\section{*Address for Correspondence}

Bradford L. Tannen, M.D., Department of Ophthalmology, Mount Sinai School of Medicine, 17 East 102nd Street, 8th Floor, Box 1183, New York, NY 10029, USA, Tel: (212) 241-0939; Fax: (212) 824-2325; E-mail: Bradford.Tannen@mssm.edu

Submission: 29 July 2013

Accepted: 26 August 2013

Published: 30 August 2013

Reviewed \& Approved by: Dr. Yassine J Daoud

Department of Ophthalmology, Division of Cornea, Cataract, \&

Refractive Surgery Services

Wilmer Eye Institute, Johns Hopkins Medical Institutions, USA

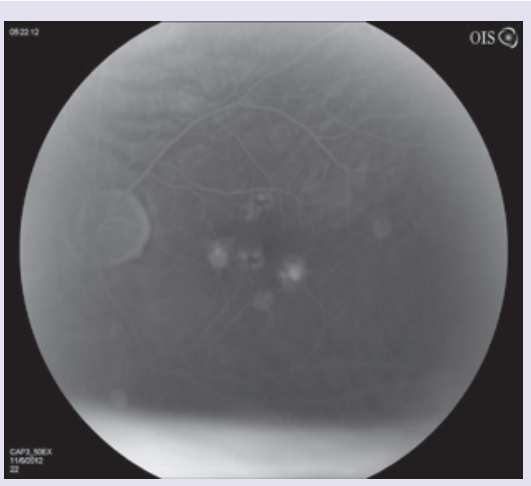

Figure 2:

secondary to blockage by RPE hyperpigmentation [1,2]. Matsushita et al. have reported thickening at the level of the outer retina/ RPE and photoreceptor IS/OS line irregularities as detected by SD-OCT that change over time with at least partial restoration [3]. Fundus autofluorescence has been described as a stippled hyperautofluorescence pattern in the acute phase followed by a more stellate pattern in the late phase. ICG has demonstrated choroidal vascular inflammation [4].

Originally described by Robinson et al. in 1958, hand-foot-mouth disease occurs as an outbreak of vesicular and ulcerative stomatitis associated with a maculopapular rash and vesicles on the hands and feet [5]. Hand-foot-mouth disease is usually a self limited condition in children. Most frequently, it is associated with coxsackie virus serotype A16 and enterovirus 71.

Differential diagnosis includes central serous retinopathy and idiopathic choroidal neovascularization. In this case, the presentation included a visual complaint of recent onset of four simultaneous scotomas that correlated with four macular lesions, in the setting of hand-foot-mouth disease, strongly favoring the diagnosis of UAIM.

This case demonstrates the clinical presentation, including fluorescein angiography and OCT findings, of presumed unilateral 
Citation: Sheyman A, Pahk P, Tannen B. Unilateral Acute Idiopathic Maculopathy Associated with Hand-Foot-Mouth Disease. J Ocular Biol. 2013;1(1): 2.

\section{ISSN: 2334-2838}
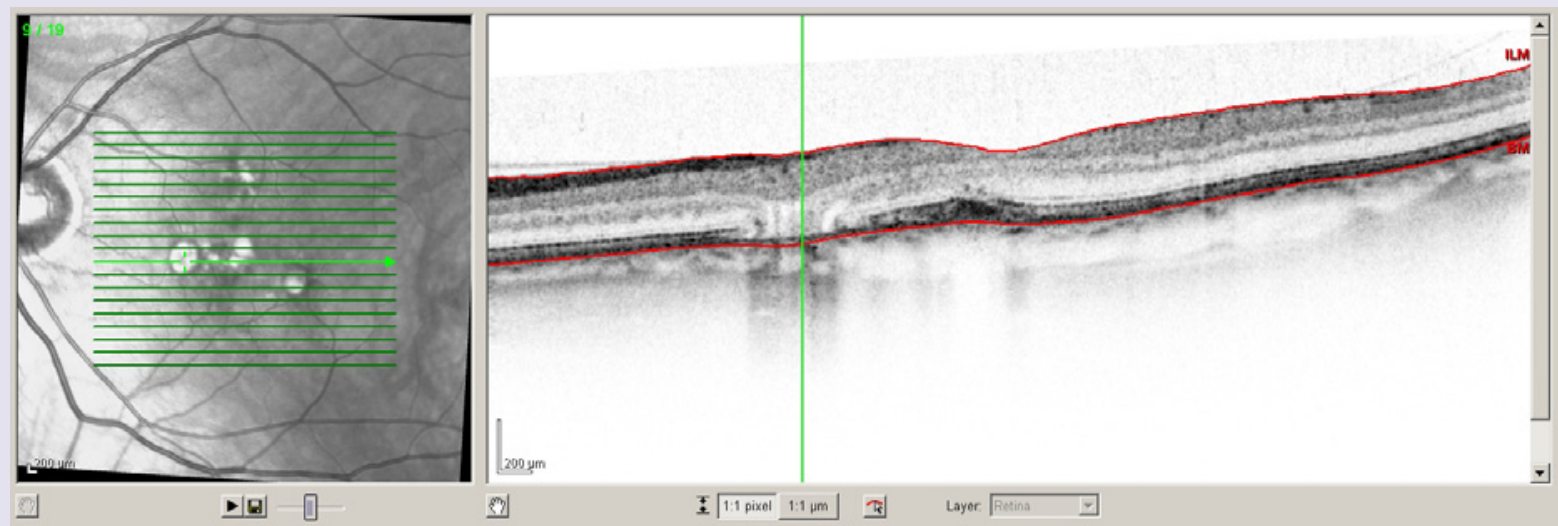

$\rightarrow[-[]$

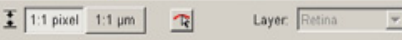

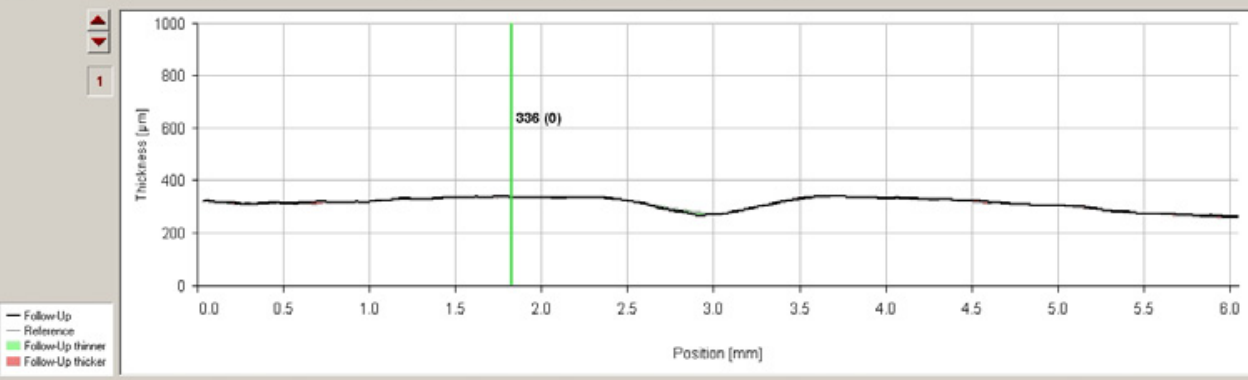

Figure 3:

acute idiopathic maculopathy. Patients may present with scotomas that are consistent with fundus examination and changes that are consistent with an outer retinopathy. Patients with active or a recent history of hand-foot-mouth disease can demonstrate these macular changes.

\section{References}

1. Yannuzzi LA, Jampol LM, Rabb MF, Sorenson JA, Beyrer C, et al. (1991) Unilateral acute idiopathic maculopathy. Arch Ophthalmol 109: 1411-1416.

2. Freund KB, Yannuzzi LA, Barile GR, Spaide RF, Milewski SA, et al. (1996) The expanding clinical spectrum of unilateral acute idiopathic maculopathy.
Arch Ophthalmol 114: 555-559.

3. Matsushita E, Fukuda K, Nakahira A, Kishi S, Fukushima A (2012) Resolutoin of photoreceptor outer segment damage in a patient with unilateral acute idiopathic maculopathy observed using spectral-domain optical coherence tomography. Graefes Arch Clin Exp Ophthalmol 250: 765-768.

4. Jung CS, Payne JF, Bergstrom CS, Cribbs BE, Yan J, et al. (2012) Multimodality diagnostic imaging in unilateral acute idiopathic maculopathy. Arch Ophthalmol 130: 50-56.

5. Robinson CR, Doane FW, Rhodes AJ (1958) Report of an outbreak of febrile illness with pharyngeal lesions and exanthema: Toronto, summer 1957; isolation of group A Coxsackie virus. Can Med Assoc J 79: 615-621.
Copyright: (c) 2013 Sheyman A, et al. This is an open access article distributed under the Creative Commons Attribution License, which permits unrestricted use, distribution, and reproduction in any medium provided the original work is properly cited. 